\title{
What's the point of reflective writing?
}

\section{John Launer}

I was recently drawn into a friendly debate on Twitter about the value of reflective writing for doctors. In the United Kingdom, all doctors are now required to record written reflections on their learning, as part of their annual appraisals. For general practitioners (GPs) these reflections have to cover a wide range of their experience during the past year. This includes clinical cases, feedback from peers and patients, quality improvement, and any complaints or significant untoward events that may have occurred. Some doctors find this arduous, and question whether it has ever improved anyone's performance as a doctor. Others, including myself, enjoy the act of writing and find it a useful way of processing complex events or seeing them in a more objective light. However, I do have some sympathy with the sceptics. Most doctors have never had any training in reflective writing. Colleagues who carry out appraisals are unlikely to have been taught how to read such reflections critically, to judge their quality, or to make the exercise a fruitful one. As a result, the experience can be dismal, and may make it seem as if reflective writing is another pointless demand placed on busy clinicians by bureaucrats and academics with nothing better to do.

In spite of this, I think there are several reasons why we should welcome the appearance of reflective writing on the medical scene. In the past, being literate was regarded as an essential part of being a professional. Doctors had to write extended essays to pass any exam, and medical teachers took it for granted that there was an inseparable link between clear writing and logical thinking. This tradition has largely died out, but there has been a general deterioration in medical literacy as a result. Compare, for example, the opening sentences from these two articles, written in 1925 and 2013 respectively, on similar subjects.

'Vertigo may be quite briefly defined as a subjective sensation of instability. It is a departure from the normal sense of equilibrium, which in health is hardly perceptible, though it plays a part in the general sense of well-being'. ${ }^{1}$

Correspondence to Dr John Launer, Faculty Development, Health Education England, Stewart House, 32 Russell, London WC1B 5DN, UK; john.launer@nwl.hee.nhs.uk
'Tinnitus is the perceived sensation of sound in the absence of a corresponding external acoustic stimulus. Unlike auditory hallucinations, which are phantom phenomena that occur mainly in people with mental disorders and manifest as the perception of voices and musical hallucinations, in which instrumental music or sound is perceived, tinnitus sensations are usually of an unformed acoustic nature such as a buzzing, hissing, or ringing'. ${ }^{2}$

As you will have noticed, the earlier article is a model of clear communication, with short words and short sentences, and has a rather human feel to it. By contrast, the more recent one is an abstract, polysyllabic muddle, and hard to follow without reading it twice-typical of much medical prose nowadays.

\section{ORIGINAL THOUGHTS}

As well as restoring the general level of literacy among doctors, there are more important reasons for encouraging doctors to learn to write well. The act of writing itself creates new and original ideas. By recalling an event, slowing it down in your mind, and anatomising it in writing, you can deepen your understanding of it, and even alter your perception of what happened. The poet William Wordsworth described this process as 'emotion recollected in tranquillity'. ${ }^{3}$ You can experience this yourself by carrying out a simple exercise. Try recalling one episode from your working day that you felt was unresolved. It may have been an incident that made you anxious, or upset, or cross. Write down three sentences about it, and then shut your eyes for a couple of minutes to think about it. When you open your eyes, write down three more sentences about it, and then repeat the procedure for as long as you want. In a relatively short space of time, you can produce a couple of paragraphs or even a page or two of reflections. Possibly, you will by now have considered a number of wider contexts and relevant facts that did not seem important at the time, but came to mind as you reflected. You will almost certainly find that this has led you to a different perspective on what happened. People doing this exercise commonly report that it makes them feel more philosophical about the event they focussed on, and less judgemental-towards themselves, or others. There are a number of courses, books and resources available that offer similar kinds of exercise, in order to develop the quality of one's reflective writing. ${ }^{5}$ These can be particularly useful for doctors who are working in a second language, and can help them indirectly with their speaking skills as well.

Many educators believe that training in reflective writing can improve physician empathy and professionalism. They see it as a form of self-supervision, offering similar benefits to the ones that arise from live supervision with peers. In some medical schools, students now learn to write reflections on their encounters with patients, as part of their professional development. The students discuss what they have written with their teachers, and receive feedback on this alongside their other clinical skills. ${ }^{6}$ Although there is a risk of students 'gaming,' and trying to manufacture evidence of their own compassion, this is probably no greater than it is with other aspects of competence that are now assessed almost everywhere-such as history-taking and communication skills. Proper training in reflective writing may make an important contribution to reflective practice, and hence improve the quality of care that students offer to patients.

Research into the effectiveness of reflective practice is only at an early stage. ${ }^{8}$ There is also a danger that training in reflection can become reductionist, serving narrow purposes such as assessment, rather than encouraging genuinely broader understanding. ${ }^{9}$ However, in the long term, I expect that reflective writing will join the list of activities that many doctors regarded as irrelevant and intrusive when they were first introduced, then came to accept with reluctance, and finally saw as an essential part of being a competent professional. Historically, these activities have included not only specialty training and postgraduate qualifications, but medical certification itself. I believe there is likely to be a gradual improvement in the quality of how reflective writing is taught, how it is done, and the benefits that practitioners see as a consequence in their day-to-day work with patients and colleagues. Whether in medical school, annual appraisal or in other forms of training and assessment, reflective writing as part of a medical career is almost certainly here to stay.

Twitter Follow John Launer at @JohnLauner

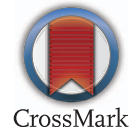

To cite Launer J. Postgrad Med J 2015;91:357-358. 


\section{On reflection}

Postgrad Med J 2015;91:357-358.

doi:10.1136/postgradmedj-2015-133514

\section{REFERENCES}

1 Symonds CY. Vertigo. Postgrad Med J 1925;1:63-5.

2 Langguth B, Kreuzer PM, Kleinjung $T$, et al. Tinnitus: causes and clinical management. Lancet

2013; 12:9203-930.

3 Wordsworth A. Lyrical Ballads. Vol. 1, 2nd Edn. London: Longman and Rees, 1800.
4 Allen H. Reflection and Reflective Writing Skills. London: London Deanery, 2013. http://www.lpmde.ac.uk/ professional-development/elearning-support-and-selfreview-modules/reflective-writing-skills/files/reflectionand-reflective-practice.pdf (accessed 29 Apr 2015)

5 Bolton G. Reflective Practice: Writing and Professional Development. 4th Edn. London: Sage, 2014.

6 Wald HS. Guiding our learners in reflective writing: a practical approach. Lit Med 2011;29:355-75.

7 Reis SP, Wald HS, Monroe AD, et al. Begin the BEGAN (The Brown Educational Guide to the Analysis of Narrative)—A framework for enhancing educational impact of faculty feedback to students' reflective writing. Patient Ed Couns 2010;80:253-9.

8 Mann K, Gordon J, MacLeod A. Reflection and reflective practice in health proessions education: a systematic review. Adv in Health Sci Ed 2009;14: 595-621.

$9 \mathrm{Ng} \mathrm{SI}$, Kinsella EA, Friesen F, et al. Reclaiming a theoretical orientation to reflection in medical education research: a critical narrative review. Med Ed 2015;49:461-75 